\title{
Paediatric Wards: Healing environment assessment
}

\author{
Roslinda Ghazali1 ${ }^{1}$, Mohamed Yusoff Abbas² \\ ${ }^{1}$ Postgraduate student, cE-Bs, FAPS, Universiti Teknologi MARA, Malaysia \\ ${ }^{2} \mathrm{Head}$, Centre for Environment-Behaviour Studies (cE-Bs), FAPS, Universiti Teknologi MARA, Malaysia \\ lindakeruing@gmail.com
}

\begin{abstract}
Malaysian paediatric wards were assessed on their quality status and design trends towards the creation of the healing environment. The objective was to promote best practices in design. PostOccupancy Evaluation (POE) studies were conducted upon paediatric wards in eight hospitals in the Klang Valley. The methodology adopted was the use of UK's NHS AEDET and ASPECT Evaluation toolkits, which evaluated the physical qualities and staffs \& patients satisfaction levels respectively upon 215 nurses and 217 patients. Results seemed to show the disparity between the positivity of the physical design in relation to users' satisfaction. Implications of the findings are discussed.

Keywords: Healing Environment, Paediatric Wards, Methodology, Evaluation toolkits

eISSN 2514-751X @ 2017 The Authors. Published for AMER ABRA by e-International Publishing House, Ltd., UK.. This is an open access article under the CC BY-NC-ND license (http://creativecommons.org/licenses/by-ncnd/4.0/). Peer-review under responsibility of AMER (Association of Malaysian Environment-Behaviour Researchers), ABRA (Association of Behavioural Researchers on Asians) and CE-Bs (Centre for EnvironmentBehaviour Studies), Faculty of Architecture, Planning \& Surveying, Universiti Teknologi MARA, Malaysia.

https://doi.org/10.21834/aje-bs.v2i3.191
\end{abstract}




\subsection{Introduction}

Interests in healing environment backdated since about 2,300 years ago, but were known in different approaches, such as holistic and spiritual. They were more commonly termed as Complementary or Alternative Medicine (Huelat, 2003). Currently, there has been a sudden increase in global interest towards the creation of the healing environment (Ananth, 2008). In Malaysia, the initiatives had been envisioned by the Health Ministry since the 1990s for a more child-friendly, cheerful and safe hospital (Mathews, 1999).

"Healing environment" can be described simply as the overall environment (both physical and non-physical) created to aid the recovery process. In contrast to curing, healing is a psychological and spiritual concept of health. Since perception is also psychological, there is a likelihood of a relationship between healing and the physical environment. Also, as the paediatric population tended to be more sensitive than adults in the perception of the environment (Ozcan, 2006), this paper posits that the quality of paediatric wards could greatly influence the recovery process of the paediatric population.

Has the 1990's vision of the Malaysian Health Ministry been transformed into reality? The present study assessed the design trend towards the creation of a healing environment in Malaysian paediatric wards. The purpose was to identify whether factors, facilities and provisions in terms of the physical qualities towards the creation of such environment were given due to considerations in relation to users' satisfaction levels in the design of those wards. It also attempted to identify possible problems that might have impeded the process towards achieving such environment.

The objective of the study was to promote best practices as a guideline for designers to further enhance the creation of a more conducive healing environment, not only for the design of new wards, but also in improving existing wards.

\subsection{Literature Review}

The literatures reviewed concerned the healing environment framework and supporting evidences of the role of the physical environment towards the creation of healing environment.

\subsection{Healing Environment Framework}

In the United States, the Samueli Institute, a medical research organization exploring the science of healing has developed the "Optimal Healing Environment" (OHE) which it described as "the social, psychological, physical, spiritual, and behavioral components of healthcare support and stimulate the body's innate capacity to heal itself" (Ananth, 2008, p. 273). The approach involved both the Inner and Outer Environment comprising of seven components as shown in Figure 1. The Inner Environment comprised three components Developing Healing Intention, Experiencing Personal Wholeness and Cultivating Healing Relationship, while the Outer Environment comprised the other four components - 
Practicing Healthy Lifestyles, Applying Collaborative Medicine, Creating Healing Organization, and Building Healing Spaces.

\begin{tabular}{|c|c|c|c|c|c|c|}
\hline $\begin{array}{l}\text { Dev. Healing } \\
\text { mendion }\end{array}$ & $\begin{array}{l}\text { Experiencing } \\
\text { Persanal } \\
\text { Whaleness }\end{array}$ & $\begin{array}{l}\text { Cuttirating } \\
\text { Healisg } \\
\text { forationship }\end{array}$ & $\begin{array}{l}\text { Practichng } \\
\text { Heathy } \\
\text { thestyles }\end{array}$ & $\begin{array}{l}\text { Applying } \\
\text { Collabeeative } \\
\text { Hediche }\end{array}$ & $\begin{array}{l}\text { Creasiag } \\
\text { Healing } \\
\text { arganisation }\end{array}$ & $\begin{array}{l}\text { Building } \\
\text { Healing } \\
\text { Spaces }\end{array}$ \\
\hline Expectation & Sind & Compassion & Ciet & Convertionat & Leadership & Hature \\
\hline Bope & Body & Enapathy & Exercise & Complementary & Hission & Celaer \\
\hline Understanding & sient & social suppoit & Relaxation & Iradetionat & Culture & Lighti \\
\hline \multirow[t]{4}{*}{ Beliet } & Enargy & Comneunication & Balance & Integrative & Teammork & Artwork \\
\hline & & & & & Technobogy & Architecture \\
\hline & & & & & Exstuation & Aroma \\
\hline & & & & & Servict & Music \\
\hline \multirow[t]{2}{*}{$\begin{array}{l}\text { Enbawce } \\
\text { Auswesess }\end{array}$} & $\begin{array}{l}\text { Enhative } \\
\text { Antrgyobon }\end{array}$ & $\begin{array}{c}\text { Enbance } \\
\text { Cosing }\end{array}$ & $\begin{array}{l}\text { Endwance } \\
\text { Awoveorss }\end{array}$ & $\begin{array}{c}\text { Enbance } \\
\text { AedicalCove }\end{array}$ & $\begin{array}{l}\text { Enhewore } \\
\text { Prokess }\end{array}$ & $\begin{array}{c}\text { Entharice } \\
\text { Sensory lqupet }\end{array}$ \\
\hline & & IHER EMUIR०MMM & & ER EMUROANEM & & \\
\hline
\end{tabular}

Where nocial, psychologital, phytical, spiritual snd behavioral cosponerts of hashthtare sepport and stinutate the body's imate casocty to hod not.

Figure 1: The Optimal Healing Environment (OHE) Framework

Source: Sita Ananth (2008), Healing Environments: the next natural step, Explore, Vol 4, No. 4, p. 274

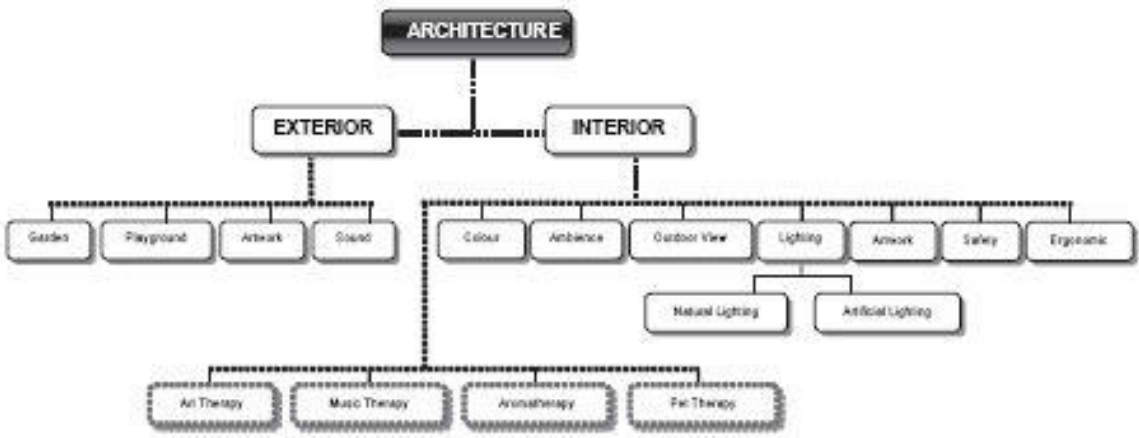

Figure 2. Modification from Ananth's (2008) Optimal Healing Environment

The OHE framework provided a wholesome and inclusive approach towards the healing process. However, both the present authors (of architectural background) opined that the 'Building Healing Spaces' component, the focus of the present study required further 
modification and refinement. The OHE modified version framework proposed, which also formed the framework of the present study is as shown in Figure 2.

In the modified model, Architecture comprises both Interior and Exterior Environments, with the various influencing factors towards healing being sub-categorised accordingly under those environments. Those previously identified elements not only contributed towards the healing process but also helped the pediatric patients to cope with pain and aggression. This was concurred by the National Association of Children's Hospitals and Related Institutions (NACHRI) where it revealed that the physical environment of healthcare settings affected the clinical, physiological, psychosocial, and safety outcomes among child patients and families (Oberlin, 2008).

\section{Interior Environment}

Elements within the Interior Environment towards the creation of a healing environment include safety, ergonomics, colour, artwork, lighting, outside view, furniture and furnishings, ambience and therapies.

The creation of a much safer environment in paediatric wards had been raised by many authors. For example, Scanlon et. al., (2006) found that there more potential risks for harm amongst paediatric patients due to their dynamism. Similarly, Woods, et. al. (2005) cautioned that patient- specific setting increased vulnerabilities, hence the consideration of patient safety in the design or improvement interventions. Earlier, Miller and Zhan (2004) revealed that events affecting patients' safety frequently involved the very young with substantial increase in their duration of stay.

Directly related to safety is the ergonomic considerations for the paediatric patients. The related implications had concerned many because the requirements of the children were not the same as the adults (Lueder, 2003). Furthermore, children were in continuous development - physically, perceptually, cognitively and socially (Lueder and Rice, 2007). Croasmun (2004) argued that often products or services might have been designed without sufficient knowledge of the end users.

Colours and artwork in children's hospital also provided a more cheerful environment hence, contributed towards the paediatric patients' healing process (Eisen, 2006). While Park (2007) revealed that the use of more colours eventually created better environments for children and their families, Daykin (2008) found that exposure to art in healthcare environments reduces anxiety and depression.

Windows with day lighting and outside view are also important contributors towards healing. For example, Beauchemin and Hays (1996) revealed that a bright light is an effective therapy used as treatment of depressive illness. He also found that patients warded in bright and sunny rooms experienced shorter period of stay compared to those in dull rooms. Ulrich, (1984) revealed that patients with windows heal faster than patients without outside view.

Moran (1993) discovered that hotel-like elements that emphasize hospitality and comfort could reduce anxiety and promote healing. The ambience should be as personal as possible such as homelike environment. Similarly, the effect of furniture arrangements in the activity 
room could promote improvements in the wards' psychosocial atmosphere, as reported by Baldwin (1985).

Various therapies have also proven to aid healing. These include therapies such as Art Therapy Malley (2002), Music Therapy Stewart (2009) Aroma Therapy (Bonadies, 2009) and Pet Therapy (Braun, et al. 2009).

\section{Exterior Environment}

Exterior or outdoor environment that could contribute towards the healing environment involved nature and the outdoor children's playground. The role of nature or the creation of therapeutic gardens towards the healing process had been reported by several studies. They include findings on garden features (Annunziato, 2002, Whitehouse, et al., 2001), different categories of garden users (Sherman, et al., 2005), play garden - an integration of playgrounds and healing gardens located in a pediatric hospital (Turner, 2009). Similar findings were also reported locally by Said (2009). In addition, NACHRI (2008) concluded that those gardens could help reduce patients' anxiety.

Table 1: Hospitals involved based on the year built

\begin{tabular}{|c|c|c|c|c|}
\hline & HOSPITALS & YEAR & AREA & NO OF BEDS \\
\hline 1 & KG & 1985 & Urban & 36 \\
\hline 2 & IP & 1991 & Urban & 32 \\
\hline 3 & KJ & 1999 & Urban & 40 \\
\hline $\mathbf{4}$ & PA & 1999 & Urban & 28 \\
\hline $\mathbf{5}$ & SG & 1999 & Non-Urban & 28 \\
\hline 6 & SD & 2005 & Non-Urban & 28 \\
\hline $\mathbf{7}$ & AG & 2006 & Non-Urban & 28 \\
\hline 8 & SB & 2007 & Non-Urban & 28 \\
\hline
\end{tabular}

\subsection{Methodology}

\subsection{Strategy}

The strategy involved Post-Occupancy Evaluation (POE) upon paediatric wards in eight hospitals located both in urban and non-urban areas in the Klang Valley. The hospitals involved were strategically identified in terms of the year they were built which represented the design of the last three decades - the 1980s, 1990s and 2000s as shown in Table 1. It was envisaged that samples for such purposeful selection could depict the design trend of such building type through those previous decades.

\subsection{Method}

The method adopted for data collection were the use of UK's NHS AEDET Evolution and ASPECT Evaluation Toolkits (DH Estates and Facilities, 2008,a, b). Questionnaires, 
personal site observation and photographic documentation supplemented the toolkits' evaluations. The AEDET (Achieving Excellence Design Evaluation Toolkit) Evolution is part of a benchmarking tool which assisted in measuring and managing the design quality in the healthcare facilities. In terms of reliability, it includes references to evidence based design literature and this is related to the criteria used in the evaluation. In terms of validity, its use is mandatory in business case submissions for major capital development. It evaluates a design through a series of statements which encompassed the three areas. The Impact Area deals with the degree to which the building created a sense of place and contributed positively to the lives of the users and its neighbours. It involves four sections - Character and Innovation, Form and Materials, Staff and Patient Environment, and Urban and Social Integration. The Build Quality Area deals with the physical components of the building rather than the spaces and involves three sections - Performance, Construction, and Engineering. The Functionality Area deals with issues on the primary purpose of the building and involves three sections - Use, Access, and Space. The ASPECT (A Staff and Patient Environment Calibration Toolkit) measures the manner the healthcare environment can impact both on the satisfaction levels to patients, and provision of facilities to staff. It evaluates eight sections - Privacy, Company and Dignity; Views; Nature and Outdoors; Comfort and Control; Legibility of Place; Interior Appearance; Facilities; and Staff. In terms of reliability and validity, the ASPECT is based on a database of over 600 pieces of research. The ASPECT Evaluation, in the form of questionnaires assessed users' satisfaction of both nurses and patients. An overall total of 215 nurses and 217 patients (aided by parents) responded to the questionnaires. Personal site observation and photographic documentation of the wards' ambience supplemented the information required to be filled in the AEDET forms. In addition to the evaluation which used both the AEDET and ASPECT toolkits, the personal site observation also made notations on the existence of the other therapies mentioned earlier.

\section{Procedure}

Prior to the site visits, consents were first obtained from the Malaysian Ministry of Health and the directors of the hospitals identified through formal applications. Preceded by initial briefings about the setup of the hospitals, representatives from the hospitals accompanied the site visits and provided responses to spontaneous general enquiries about the physical environment of the wards. Data collected involved personal observations made with notations and photographic documentations about the facilities provided and on the overall ambience. The AEDET Evolution toolkits forms were then filled. Visits to the hospitals were done once and lasted about 4 hours per hospital. Evaluation of ASPECT involved questionnaires distributed to staffs and patients' carers in the wards. The staff aided with the questionnaires distribution. Questionnaires were completed and collected later after about four weeks. 


\section{Delimitations}

The study was delimited to 30-40 bedded paediatric wards, so that comparison could be made with the newer wards built which were limited to those numbers of beds due to current hospital policy. Patients focussed were those ages between 3-6 years old.

\section{Limitations}

Limitations of the research involved time constrains and questionnaires feedbacks from patients' cooperation. Prior to the data collection stage, time was used in getting approval from the Health Ministry due to having to meet the procedural compliances as set by the Malaysian National Medical Research Institute. Questionnaires feedbacks from patients involved co-operation from the parents involved.

\subsection{Results and Discussions}

\subsection{UK's NHS Evaluation Toolkits}

\section{AEDET Evolution Evaluation}

Based on the AEDET Evolution evaluation upon the physical qualities of the eight wards, overall the findings seemed to reveal a positive trend towards the creation of a healing environment as shown in Figure 3.
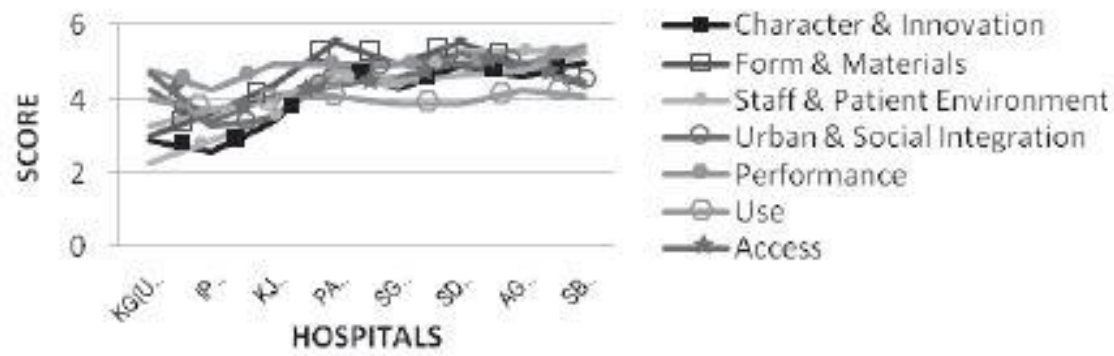

Figure 3: The AEDET (Achieving Excellence Design Evaluation Toolkit) Evaluation Summary of Findings

Amongst the most marked positive trends from the sections analysed were the Staff \& Patient Environment, and Space sections. However, those that initially showed a positive trend but somehow declined were from 2005 the Urban \& Social Integration, and the Access sections, while from 1999 were, the Character \& Innovation, and Form \& Materials sections. The Performance section seemed to have improved only from 2006 after being 
idled over the previous decades. Not much change in trend was recorded in the Use section.

\section{ASPECT Evaluation}

Feedbacks in satisfaction levels on provisions and facilities available from the questionnaire respondents involved in the eight wards were received from an overall total of 215 staffs (nurses) and 217 patients. Feedbacks requested from staffs involved four main categories (with several criteria per category) -

View to Outside; Nature \& Outdoor; Comfort \& Control; and Staff Facilities. Feedbacks requested from patients involved the first there categories, with the addition of four more categories - Privacy, Company \& Dignity; Legibility of Place; Interior Appearance; and Facilities for Users. Results of the findings is presented in the form of colour patterns to indicate their satisfaction levels for the staffs and patients are as shown in Figure 4.1 and Figure 4.2 respectively.

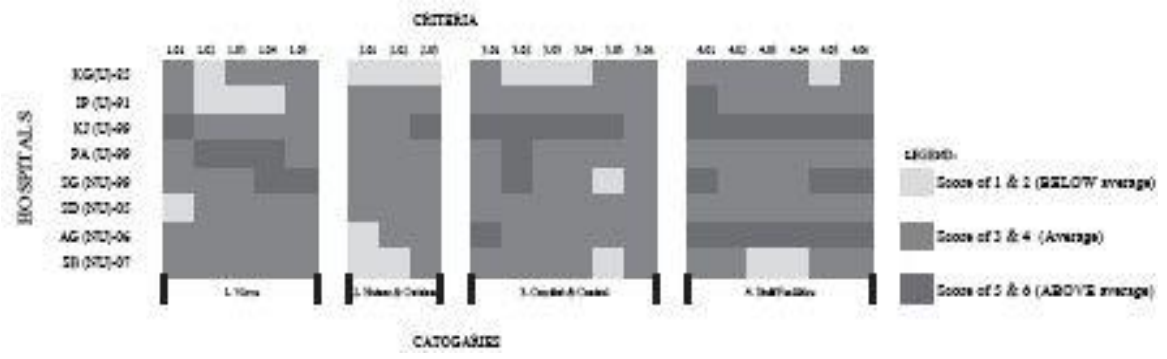

Figure 4.1: The ASPECT (A Staff and Patient Environment Calibration Toolkit) - Summary of Findings (Staffs, $\mathrm{N}=215$ )

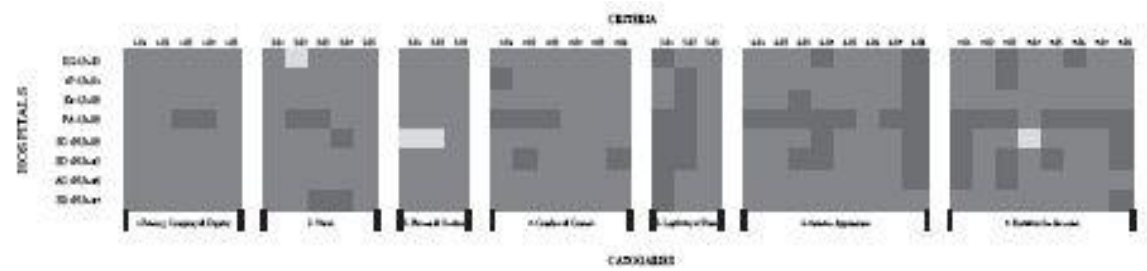

Figure 4.2 The ASPECT (A Staff and Patient Environment Calibration Toolkit) - Summary of Findings (Patients, N=217)

From the findings shown in Figure 4.1, it seemed that the overall staff' satisfactory level were highest for the older $\mathrm{KJ}(\mathrm{U})-1999$ hospital and followed by the newer $\mathrm{AG}(\mathrm{NU})-2006$ hospital. While it was not surprising for the oldest $K G(U)-1985$ hospital to be rated the 
lowest, most surprising was the newest $\mathrm{SB}(\mathrm{NU})$-2007 hospital given below average rating in three categories - Nature \& Outdoor, Comfort \& Control and Staff Facilities.

Similarly, the patients' satisfactory level was highest for not the newest SB(NU)-2007 hospital but rather for the newer PA(U)-1999 hospital, and then with continuous positive trends for the other newer hospital over the decades in only the three categories - Legibility of Place, Interior Appearance, and Facilities for Users, as shown in Figure 4.2. In comparing the satisfactory levels between the staff' and the patients' in the three categories - View to Outside, Nature \& Outdoor, and Comfort \& Control, it seemed that overall, the patients were more satisfied than the staff with the facilities and provisions, although not necessarily in correlations with the ascending years the hospitals were built.

In addition, the findings evaluated in ASPECT (data collapsed for both staff and patients) did not seem to tally with findings evaluated in AEDET, whereby the overall physical qualities of the hospitals revealed a more positive trend as shown in Figure 4.3. This indicates that if the quality status and design trend of the wards were truly positive towards the creation of the healing environment, the trend of end users' satisfaction level should have shown one of the increments in the progression of the decades.

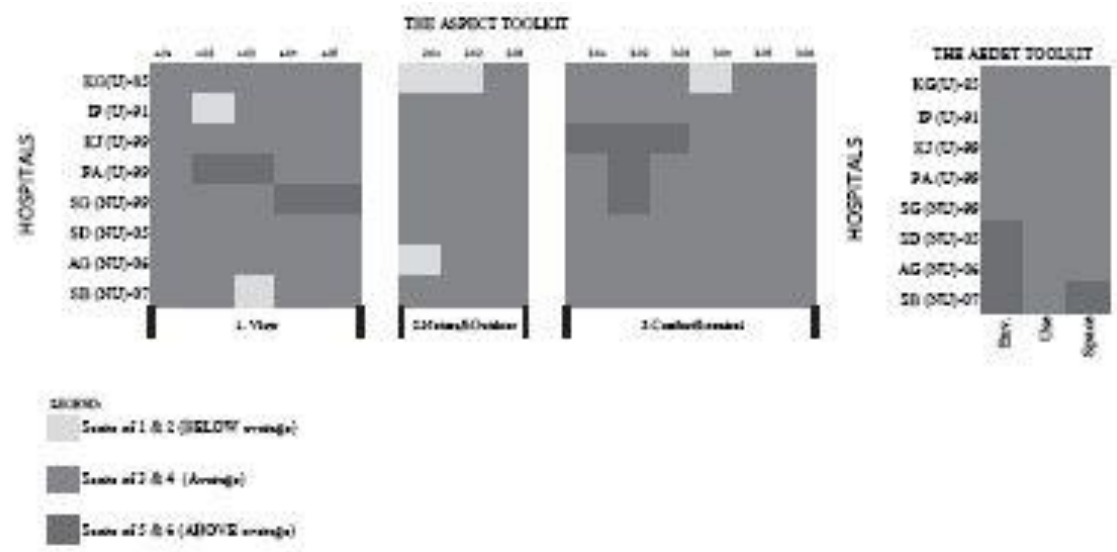

Figure 4.3 Correlation between the ASPECT and AEDET Evaluation Toolkit

Could the other therapies mentioned earlier, play a major role towards the end users' satisfaction and thus influencing the healing process? Those were almost non-existent in all the newer wards, except for one of the older wards in the use of Art therapy, where patients together with the nurses painted murals along the corridor.

Also, this study is focused only on one of the seven components in The OHE Framework as shown in Figure 1. Hence, the other six components, which were not measured, could also have greatly influenced the satisfaction levels. Interestingly, if both the AEDET and ASPECT evaluations indicated a similar positive trend, than it can be 
argued that the physical environment component would be the most significant component as compared to the other six components in the creation of the OHE. Since that was not the case, the findings further strengthened the contribution of the other six components in the creation of the OHE.

\subsection{Conclusion}

The overall physical qualities and design trend of the wards over the last three decades seemed to be positive towards the creation of the healing environment. The trend however, seemed not to correspond with the satisfaction levels of the end users. Perhaps, the users' satisfaction levels could have shown a more positive trend, if the other additional therapies art, music, pet and aromatherapy - which were almost absent in all the wards, were provided in the newer wards. In addition, positive trends in the other six components shown in Figure 1, excluded from this study could also have major influences positively upon the users' satisfaction levels.

For best practice, apart from understanding the behavioural needs of the end users, there should be inclusion of other additional therapies - art, music, pet and aromatherapy in the design brief.

\section{Acknowledgement}

Our heartiest gratitude to the Malaysian Ministry of Higher Education for the research grant awarded for this study.

\section{Special Note}

This paper was developed further from the paper published by the same authors in Healing environment of pediatric wards, Procedia - Social and Behavioral Sciences, 5, 2010, 948957, Elsevier, available online 21 September 2010. Earlier findings were revealed in the Proceedings of AcE-Bs 2010, Riverside Majestic Hotel, Kuching, Malaysia, 7-8 July 2010, while the pilot study in the Proceedings of 1nCEBS 2009, Shah Alam, Malaysia, 14-15 November 2009.

\section{References}

Ananth, S., (2008), Healing Environments: the next natural step, Explore, 4(4), 274

Annunziato, L., (2002), Playful Pediatrics, Contract San Francisco: 44(9), 7674 Baldwin, S., (1985), Effects of furniture rearrangement on the atmosphere of wards in a maximum-security hospital, Hospital and Community Psychiatry: 36(5), 525-528

Moore, D.J.J., (2000), Designed to Heal Modern Healthcare, Chicago, 30(47), 32, 
Moran, T., (1993) Hospital Hotel Crain's Detroit Business. Detroit, 9(18), 11.

Morrison, M. L., (2007), Health Benefits of Animal-Assisted Interventions, Complementary Health Practice Review:. 12(1), 51-62 NACHRI (2008), Evidence for Innovation, National Association of Children's Hospitals and Related Institutions (NACHRI) Issue http://www. healthcaredesignmagazine.com, Date: Online, Posted On: $7 / 8 / 2008$

Oberlin, J., (2008), Evidence that pediatric settings can heal, Health Care Design, http://www.healthcaredesignmagazine.com/ME2/dirmod.asp?sid=\&nm=\&type=Publishing\&mod=Publications\%3A \%3AArticle\&mid $=\quad$ 8F3A7027 $\quad$ 421841978F18BE895F87F791\&tier=4\&id=92860F707A534EE6A9266D C828E2FBCA, Date: Online, Posted On: 7/8/2008

Ozcan, H. (2006) Healing Design: A Holistic Approach to Social Interaction in Pediatric Intensive Care Units in the United States and Turkey, PhD Dissertation, Texas A \& M University, USA

Park, J.G., (2007), Environmental Color For Pediatric Patient Room Design, PhD Dissertation, Texas A\&M University

Said, I., (2009), Garden as restorative environment for hospitalized children, Universiti Teknologi Malaysia.

Scanlon, M., (2007), Human Factors and Ergonomics in Pediatrics in Pascale Carayon (Ed) Handbook of Human Factors and Ergonomics in Health Care and Patient Safety, Lawrence Erlbaum Associates, London, 865-882

Sherman, S. A., Varni, J. W., Ulrich, R. S. \& Malcarne, V. L.,(2005), Post-occupancy evaluation of healing gardens in a pediatric cancer center, Landscape and Urban Planning: 73(2-3), 167-183

Turner, J., Fralic, J., Newman-Bennett, K. and Skinner, L., (2009), Everybody Needs a Break! Responses to a Playgarden Survey , Pediatric Nursing, 35 (1), 27

Ulrich,R.S., (1984) ,View through a window may influence recovery from surgery, Science : 224( 4647), 420-421

Whitehouse, S., Varni, J.W., Seid, M., Cooper-Marcus, C., Ensberg, M.J., Jacobs, J.R., and Mehlenbeck (2001), Evaluating a children's hospital garden environment utilization and consumer satisfaction, Journal of Environmental Psychology, 21, 301-314

Woods, D., Holl, J. L., Shonkoff, J. P., Mehra, M., Ogata, E.S., Weiss, K.B., (2005), Child Specific Risk Factors and Patient Safety, Journal of Patient Safety, 1(1), 17-22 